\title{
Rhizome elongation and seagrass clonal growth
}

\author{
Núria Marbà ${ }^{1, *}$, Carlos M. Duarte $^{2}$ \\ ${ }^{1}$ Centre for Estuarine and Coastal Ecology, NIOO, Korringaweg 7, 4401 NT Yerseke, The Netherlands \\ ${ }^{2}$ Centre d'Estudis Avançats de Blanes, CSIC, Camí de Sta. Bàrbara s/n, E-17300 Blanes, Spain
}

\begin{abstract}
A compilation of published and original data on rhizome morphometry, horizontal and vertical elongation rates and branching patterns for 27 seagrass species developing in 192 seagrass stands allowed an examination of the variability of seagrass rhizome and clonal growth programmes across and within species. Seagrass horizontal rhizomes extend at rates ranging between 1.2 and $574 \mathrm{~cm} \mathrm{yr}^{-1}$, develop a branch, with an angle from 19 to $72^{\circ}$, for every 6 to 1800 horizontal internodes, and add a new shoot for every 1.1 to $7.5 \mathrm{~cm}$ of rhizome produced. Vertical rhizomes elongate at rates between 0.1 and $34 \mathrm{~cm} \mathrm{yr}^{-1}$ and the probability that they will branch varies over 3 orders of magnitude. Much (between 40 and $173 \%$ ) of the variability of seagrass horizontal rhizome and clonal growth programmes is species-specific, largely (21 to $63 \%$ of the variance) associated with differences in size among species, although seagrasses also show important intraspecific variability. The broad repertoire of seagrass rhizome and clonal growth programmes explains the different rates and efficiency at which the species occupy space. The implications of specific growth programmes for space occupation were examined by simulating the development of seagrass rhizome networks of 3 seagrass species encompassing the range of horizontal rhizome growth (Halophila ovalis, Thalassodendron ciliatum, Posidonia oceanica). This exercice showed that small, fast-growing species achieve a much lower spread efficiency ( $\mathrm{m}^{2}$ of ground covered $\mathrm{m}^{-1}$ of rhizome produced) than the large, slow-growing species. Differences in rhizome branching angles greatly constrained the form of rhizome networks. The results show that clonal growth patterns are a primary component of seagrass productivity and, therefore, the key to the development and maintenance of seagrass meadows.
\end{abstract}

KEY WORDS; Seagrasses - Clonal growth Plant allometry - Rhizome diameter - Spacer length . Rhizome elongation. Branching rate and angle

\section{INTRODUCTION}

Vegetative development is, as is the case for all clonal plants, the main mechanism for seagrass proliferation (Tomlinson 1974, Duarte \& Sand-Jensen 1990). Most seagrass shoots are produced as rhizomes grow, which is the process that regulates the rate of formation and the spatial distribution of shoots within seagrass meadows. The necessary coupling between rhizome spread and shoot population development implies that the process of rhizome growth is of central importance for predicting seagrass productivity (Tomlinson 1974) and clonal growth.

\footnotetext{
- Present address: Centre d'Estudis Avançats de Blanes, CSIC, Camí de Sta. Bàrbara s/n, E-17300 Blanes, Spain.

E-mail: marba@ceab.csic.es
}

Clonal growth depends on a set of growth rules that determine the elongation (i.e. rate of addition and size of rhizome internodes) and branching pattern (i.e. branching frequency and branching angle) of the rhizomes, and the rhizome length in between consecutive shoots (Bell et al. 1979, Bell \& Tomlinson 1980, Angevine \& Handel 1986, Cain 1990, Cain et al. 1996). Seagrass growth rules regulating rhizome elongation appear to be to a large extent species-specific, and scaled to plant size (Duarte 1991), but they also exhibit intraspecific variability allowing for adaptive responses (e.g. to sand burial, Marbà \& Duarte 1994 ; to changes in light or temperature conditions, Marbà et al. 1996a, Terrados 1997; to nutrient availability, Pérez et al. 1994). Moreover, the highly organised morphology of seagrass rhizome networks results from the control exerted by apical dominance on clonal growth (Terrados et al. 1997). 
Knowledge of the growth programme of terrestrial clonal plants has allowed the prediction of the extent and density of plant populations (Bell \& Tomlinson 1980), an examination of their foraging capacity (Cain 1990) and movement of shoots (Bell \& Tomlinson 1980), and an analysis of interactions between neighbours (Kenkel 1993). Similarly, a coherent knowledge of seagrass rhizome growth programmes should provide new opportunities to understand the patterns of space occupation, resource allocation and the competitive potential of seagrass species. Indeed, seagrass clonal growth has been demonstrated to be the basis of meadow maintenance (Vermaat et al. 1995), and the key factor in predicting colonisation rates (Duarte \& Sand-Jensen 1990, Duarte 1995) and plant survivorship after disturbances (Marbà \& Duarte 1995). Although the persistence, colonisation, and survival of seagrass meadows are clearly dependent on clonal growth, information on rhizome growth programmes is still scarce (Duarte 1991). The bulk of the research on seagrass growth has focused on leaf growth, whereas rhizome growth has been largely neglected. There are, however, signs that the early call for the study of rhizome growth as the key factor for predicting seagrass production (cf. Tomlinson 1974) is now receiving due attention (e.g. Duarte 1991, Terrados \& Ros 1992, Gallegos et al. 1993, Vermaat et al. 1995). As more data becomes available, it is now possible to attempt the needed synthesis of the available information on the rates, patterns, and intraspecific variability of rhizome spread to model clonal growth across seagrass species.

We examine here seagrass rhizome and clonal growth, and its variability across and within species, based on a broad compilation of published and original data on horizontal and vertical rhizome elongation and branching patterns of 27 seagrass species growing in 192 stands throughout the world. We test the size dependence of seagrass rhizomes and clonal growth, using rhizome diameter as a descriptor of the size of seagrass species (Duarte 1991). Lastly, we illustrate the implications of different seagrass clonal growth programmes for the space occupation of seagrass clones by simulating the clonal spread of 3 contrasting seagrass species.

\section{METHODS}

We compiled, from the published literature and unpublished sources (Table 1), available data on internodal length, elongation rate, and branching frequency of horizontal and vertical seagrass rhizomes, horizontal branching angle, horizontal rhizome diameter (hereafter referred as rhizome diameter), and hori-

Table 1. Sources of data on (1) seagrass rhizome diameter, (2) horizontal internodal length and rhizome spacing, (3) vertical internodal length, (4) horizontal rhizome elongation, (5) vertical rhizome elongation, and (6) branching rate

\begin{tabular}{|c|c|c|c|c|}
\hline Species & Source & Site & Variables & No. of stands examined \\
\hline \multirow[t]{3}{*}{ Amphibolis antarctica } & Duarte $(1991)^{d}$ & & 1,4 & \\
\hline & Marbà et al. (unpubl.) & W Australia & $1,2,3,4,5,6$ & 1 \\
\hline & Pedersen (unpubl.) & W Australia & 3,5 & 1 \\
\hline Amphibolis griffithii & Marbà et al. (unpubl.) & W Australia & $1,2,3,4,5,6$ & 1 \\
\hline \multirow[t]{5}{*}{ Cymodocea nodosa } & $\begin{array}{l}\text { Caye \& Meinesz (1985) } \\
\text { Duarte (1991) }\end{array}$ & France & $\begin{array}{c}2,3,4,5,6 \\
1,4\end{array}$ & 1 \\
\hline & Terrados \& Ros (1992) & Spain & 4 & 1 \\
\hline & Cunha (1994) & Portugal & $2,3,4,5$ & 5 \\
\hline & Duarte et al. (unpubl.) & Spain & $1,2,3,4,5,6$ & 16 \\
\hline & Marbà et al. (unpubl.) & Spain & 1,2 & 1 \\
\hline \multirow[t]{5}{*}{ Cymodocea rotundata } & Vermaat et al. (1995) & The Philippines & $1,2,3,4,5,6$ & 1. \\
\hline & Brouns (1987) & Papua New Guinea & 2,4 & \\
\hline & Duarte $(1991)^{d}$ & & 1.4 & 4 \\
\hline & Duarte et al. (unpubl.) & The Philippines & 3 & 1 \\
\hline & Duarte et al. (unpubl.) & Thailand & 3 & 1 \\
\hline \multirow[t]{5}{*}{ Cymodocea serrulata } & Brouns (1987) & Papua New Guinea & 2,4 & 1 \\
\hline & Duarte $(1991)^{\star}$ & & 1,4 & \\
\hline & Vermaat et al. (1995) & The Philippines & $1,2,3,4,5,6$ & 1 \\
\hline & Duarte et al. (1997) & The Philippines & 3 & 4 \\
\hline & Marbà et al. (unpubl.) & Kenya & 1.2 & 1 \\
\hline \multirow[t]{2}{*}{ Enhalus acoroides } & Duarte $(1991)^{\alpha}$ & & 1,4 & \\
\hline & Vermaat et al. (1995) & The Philippines & $1,2,4,6$ & 1 \\
\hline Halophila decipiens & Duarte $(1991)^{d}$ & & 1,4 & \\
\hline Halophla hawaiiana & Herbert (1986) & Hawaii & $1,2,4,6$ & 1 \\
\hline
\end{tabular}


Table 1 (continued)

\begin{tabular}{|c|c|c|c|c|}
\hline Species & Source & Site & Variables & No. of stands examined \\
\hline \multirow[t]{2}{*}{ Halophila ovalis } & Duarte $(1991)^{\circ}$ & & 1,4 & \\
\hline & Vermaat et al. (1995) & The Philippines & $1,2,4,6$ & 1 \\
\hline Halophila stipulacea & Marbà et al. (unpubl.) & Kenya & 1,4 & 1 \\
\hline \multirow[t]{2}{*}{ Heterozostera tasmanica } & Duarte $(1991)^{\mathrm{a}}$ & & 1,4 & \\
\hline & Marbà et al. (unpubl.) & W Australia & $1,2,3,4,5,6$ & 1 \\
\hline \multirow[t]{5}{*}{ Halodule uninervis } & Brouns (1987) & Papua New Guinea & 2,4 & 1 \\
\hline & Duarte $(1991)^{\star}$ & The Philingings & 1,4 & \\
\hline & Vermaat et al. (1995) & The Philippines & $1,2,3,4,5,6$ & 1 \\
\hline & Duarte et al. (1997) & The Philippines & 3 & 4 \\
\hline & Marbà et al. (unpubl.) & Kenya & 1,2 & 1 \\
\hline \multirow[t]{2}{*}{ Halodule wrightii } & Duarte $(1991)^{\mathrm{a}}$ & & 4 & \\
\hline & Gallegos et al. (1994) & Caribbean & $1,2,3,4,5,6$ & 1 \\
\hline Posidonia angustifolia & Marbà et al. (unpubl.) & W Australia & $1,2,3,4,5,6$ & 1 \\
\hline \multirow[t]{3}{*}{ Posidonia australis } & Duarte $(1991)^{\mathrm{a}}$ & & 1,4 & \\
\hline & Marbà et al. (unpubl.) & W Australia & $1,2,3,4,5,6$ & 1 \\
\hline & Pedersen (unpubl.) & W Australia & 2,4 & 1 \\
\hline \multirow[t]{6}{*}{ Posidonia oceanica } & Calmet et al. (1988) & Corsica & 5 & 1 \\
\hline & Duarte $(1991)^{z}$ & & 1.4 & \\
\hline & Meinesz et al. (1991) & France & 6 & 1 \\
\hline & Marbà et al. (1996b) & Spain & $1,2,4$ & 29 \\
\hline & Marbà \& Duarte (1997) & Spain & 3,5 & 15 \\
\hline & Marbà et al. (unpubl.) & Spain & 1 & 1 \\
\hline Posidonia sinuosa & Marbà et al. (unpubl.) & W Australia & $1,2,3,4,5,6$ & 2 \\
\hline Phylospadix scouleri & Ramírez-García et al. (1998) & 3) Baja California & 1,4 & 1 \\
\hline Phylospadix torreyi & Duarte $(1991)^{\mathrm{a}}$ & & 1,4 & \\
\hline \multirow[t]{4}{*}{ Syringodium filiforme } & Patriquin (1975) & Barbados & 4 & 1 \\
\hline & Williams (1987) & Caribbean & 1,2 & 1 \\
\hline & Duarte $(1991)^{d}$ & & 1,4 & \\
\hline & Gallegos et al. (1994) & Caribbean & $1,2,3,4,5,6$ & 1 \\
\hline \multirow[t]{4}{*}{ Syringodium isoetifolium } & Brouns (1987) & Papua New Guinea & 2,4 & 1 \\
\hline & Duarte $(1991)^{a}$ & & 1,4 & \\
\hline & Vermaat et al. (1995) & The Philippines & $1,2,3,4,5,6$ & 1 \\
\hline & Duarte et al. (1997) & The Philippines & 3 & 4 \\
\hline \multirow[t]{5}{*}{ Thalassia hemprichii } & Duarte $(1991)^{a}$ & & 1,4 & \\
\hline & Vermaat et al. (1995) & The Philippines & $1,2,3,4,5,6$ & 1 \\
\hline & Duarte et al. (1997) & The Philippines & 3,5 & 4 \\
\hline & Duarte et al. (unpubl.) & The Philippines & 3,5 & 15 \\
\hline & Marbà et al. (unpubl.) & Kenya & 1,2 & 1 \\
\hline \multirow[t]{5}{*}{ Thalassia testudinum } & Patriquin (1973) & Bermuda & 4,5 & 1 \\
\hline & Williams (1987) & Caribbean & 1,2 & 1 \\
\hline & Gallegos et al. (1993) & Caribbean & $2,3,4,5$ & 3 \\
\hline & Gallegos et al. (unpubl.) & Caribbean & 6 & 1 \\
\hline & Marbà et al. (1994) & Caribbean & 3,5 & 1 \\
\hline \multirow[t]{2}{*}{ Thalassodendron ciliatum } & Duarte et al. (1996) & Kenya & $1,2,3,4,5,6$ & 1 \\
\hline & Marbà et al. (unpubl.) & Kenya & $1,2,3,5$ & 2 \\
\hline \multirow[t]{2}{*}{ Thalassodendron pachyrhizum } & Marbà et al. (unpubl.) & W Australia & $1,2,3,4,5,6$ & 1 \\
\hline & Pedersen (unpubl.) & W Australia & 3,5 & 1 \\
\hline \multirow[t]{4}{*}{ Zostera marina } & Sand-Jensen (1975) & Denmark & 2,4 & 1 \\
\hline & Jacobs (1979) & France & 1,2 & 1 \\
\hline & Marbà et al. (1996a) & Spain & $1,2,4$ & 1. \\
\hline & Marbà et al. (unpubl.) & Spain & 6 & 1 \\
\hline \multirow[t]{4}{*}{ Zostera noltii } & Duarte $(1991)^{a}$ & & 1,4 & \\
\hline & Marbà et al. (1996a) & Spain & $1,2,4$ & 1 \\
\hline & Marbà et al. (unpubl.) & Spain & 6 & 1 \\
\hline & Marbà et al. (unpubl.) & The Netherlands & 1,2 & 1 \\
\hline
\end{tabular}


zontal rhizome length between consecutive shoots (hereafter referred as spacer length). The estimates of the dynamic properties of clonal growth included in the study were measured over annual time scales, using marking techniques (Zieman 1974) or techniques, based on age determinations, to reconstruct growth (Duarte et al. 1994). We provide estimates of horizontal and vertical branching frequency as the number of thizome internodes per branch produced (i.e. internodes branch ${ }^{-i}$ ), and we calculated the rates per unit time (i.e. branches $\mathrm{yr}^{-1}$ ) as the product of the inverse of the branching frequency and the number of rhizome internodes produced annually.

We consider individual seagrass stands as the units of this study. We use the coefficient of variation to quantify the inter- and intraspecific variability of internodal length and rhizome elongation. The relationships between components of clonal growth and the rhizome diameter across species are described by fitting allometric equations of the form $Y=a X^{b}$ (Duarte 1991, Niklas 1994) using least squares linear regression analyses on log-transformed average values for the species. We use circular statistics (Batschelet 1981) to estimate the mean branching angle for each species

We explore the implications of the differences in seagrass vegetative growth programmes for space occupation using a model which simulates, based on the specific growth programmes described, the horizontal clonal spread of 3 seagrass species encompassing a broad range of horizontal rhizome growth (i.e. Halophila ovalis, Thalassodendron ciliatum, and Posidonia oceanica). The model was designed to simulate the spread of a seagrass rhizome network by the iteration of new horizontal internodes and branches. The model contains deterministic (i.e. branching angle, internodal length, growth rate as internodes $\mathrm{yr}^{-1}$ ) and stochastic (i.e. branching probability) parameters. Whether or not a branch was produced at a new node was decided by Monte Carlo simulation based on the average branching probability. The output returned by the model consisted of the total number of

Table 2. Mean rhizome diameter (RD, in mm), horizontal internodal length (HINTL, in mm), vertical internodal length (VINTL, in $\mathrm{mm}$ ), spacer length ( $\mathrm{SL}$, in $\mathrm{cm}$ ), horizontal rhizome elongation rate ( $\mathrm{HE}$, in $\mathrm{cm} \mathrm{yr}^{-1}$ ), and vertical rhizome elongation rate (VE, in $\mathrm{cm} \mathrm{yr}^{-1}$ ) of seagrass species. Values in parentheses show the ranges of the variables per species when more than 1 stand was examined. CV: coefficient of variation

\begin{tabular}{|c|c|c|c|c|c|c|c|c|c|c|c|}
\hline \multirow{2}{*}{$\begin{array}{l}\text { Species } \\
\text { Amphibolis antarctica }\end{array}$} & \multirow{2}{*}{$\begin{array}{l}\mathrm{RD} \\
2.80\end{array}$} & \multicolumn{2}{|c|}{ HINTL } & \multicolumn{2}{|c|}{ VINTL. } & \multicolumn{2}{|r|}{$\mathrm{SL}$} & \multicolumn{2}{|c|}{$\mathrm{HE}$} & \multicolumn{2}{|r|}{ VE } \\
\hline & & 7 & & 9 & $(5-12)$ & 3.86 & & 20 & $(5-35)$ & 24 & $(7-32)$ \\
\hline Amphibolis griffithii & 2.19 & 10 & & 10 & & 6.16 & & 4 & & 16 & $(5-34)$ \\
\hline Cymodocea nodosa & 2.37 & 25 & $(6-53)$ & 1.4 & $(0.1-2.5)$ & 2.77 & $(1.1-5.5)$ & 40 & $(7-204)$ & 1.4 & $(0.1-16)$ \\
\hline Cymodocea rotundata & 2.44 & 29 & & 2 & $(0.5-5)$ & 4.8 & & 210 & $(34-411)$ & 1.5 & $(1.1-3.3)$ \\
\hline Cymodocea serrulata & 2.78 & 38 & $(35-39)$ & 5 & $(4-7)$ & 5.30 & & 153 & $(79-216)$ & 13 & \\
\hline Enhalus acoroides ${ }^{a}$ & 14.1 & 5 & & & & 6.68 & & 3 & $(0.9-5)$ & & \\
\hline Halophila desciprens & 0.8 & & & & & & & 215 & & & \\
\hline Halophila hawaiiana & 1.2 & 10 & & & & & & 89 & & & \\
\hline Halophila ovalis ${ }^{d}$ & 1.3 & 17 & & & & 1.7 & & 356 & $(141-574)$ & & \\
\hline Halophila stipulacea" & 1.12 & 16 & & & & & & & & & \\
\hline Heterozostera tasmanica & 1.74 & 20 & & 7 & & 2.07 & & 103 & $(56-150)$ & 9 & \\
\hline Halodule uninervis & 1.37 & 21 & $(9-33)$ & 5 & $(1-7)$ & 2.7 & & 101 & $(28-138)$ & 4 & \\
\hline Halodule wrightii & 1.64 & 20.2 & & 1.2 & & 2.02 & & 223 & $(81-365)$ & 3 & \\
\hline Posidonia angustufolia & 5.99 & 18 & & 10 & & 7.5 & & 12 & & 5 & $(1-11)$ \\
\hline Posidonia australis & 7.21 & 15 & $(14-17)$ & 1.5 & & 6 & & 9 & $(9-10)$ & 1 & $(0.4-6)$ \\
\hline Posidonia oceanıca & 9.7 & 3 & $(1-4)$ & 1 & $(0.4-2)$ & 2.81 & $(1.2-5.3)$ & 2 & $(1-6)$ & 1 & $(0.1-4)$ \\
\hline Posidonia sinuosa & 5.5 & 11. & $(8-14)$ & 3 & $(2-4)$ & 4.47 & $(3-5.9)$ & 4 & $(2-6)$ & 0.8 & $(0.2-8)$ \\
\hline Phyllospadix scouleri & 6.5 & & & & & & & 17 & & & \\
\hline Phyllospadix torreyi & 5 & & & & & & & 26 & & & \\
\hline Syringodium filiforme & 2.77 & 23 & $(16-31)$ & 6 & & 3.06 & & 123 & $(52-182)$ & 4 & \\
\hline Syringodium isoetifolium & 1.74 & 27 & $(25-28)$ & 11 & $(8-13)$ & 3.7 & & 109 & $(75-135)$ & 9 & \\
\hline Thalassia hemprichil & 3.63 & 4 & $(4-7)$ & 1 & $(0.5-3)$ & 6.9 & & 54 & $(21-88)$ & 3 & $(2-5)$ \\
\hline Thalassia testudinum & 5.96 & 15 & $(5-43)$ & 2 & $(7-18)$ & 7 & $(5.8-7.1)$ & 69 & $(22-152)$ & 4 & $(2-20)$ \\
\hline Thalassodendron ciliatum & 5.6 & 8 & $(6.7-10)$ & 3 & & 3.32 & $(2.7-4)$ & 16 & & 10 & $(5-10)$ \\
\hline Thalassodendron pachyrhizum & 5.64 & 5 & & 6 & $(5.2-7.35)$ & 1.9 & & 3 & $(3-6)$ & 5 & $(2.8-12)$ \\
\hline Zostera marina ${ }^{a}$ & 3.5 & 11 & $(9-12)$ & & & 6.08 & & 26 & $(22-31)$ & & \\
\hline Zostera noltii & 1.6 & 12 & $(3-20)$ & & & 2.07 & & 68 & $(10-127)$ & & \\
\hline Across species CV $(\%)$ & 80 & 58 & & 74 & & 45 & & 111 & & 89 & \\
\hline Within species CV $(\%)$ & & 36 & & 53 & & & & 72 & & 45 & \\
\hline
\end{tabular}


branches, the total length of the rhizome network, the coordinates of the starting point and the end point of each branch, and an estimation of the size of the clone, i.e. area within the perimeter of the rhizome network.

\section{RESULTS}

The data set compiled included 27 seagrass species developing in 192 stands (Table 1). The diameter of horizontal internodes ranged from 0.8 to $14.13 \mathrm{~mm}$, their length from 1.4 to $53 \mathrm{~mm}$, and the length of vertical internodes from 0.08 to $18 \mathrm{~mm}$ across the seagrass stands investigated (Table 2). Most of the variability in seagrass internodal length is attributable to species-specific differences in the architecture of seagrasses (Table 2). The variability in the length of horizontal internodes was found to be strongly size-dependent, and to be scaled as the $-1 / 2$ power of rhizome diameter (Table 3 ). Large species, with thick rhizomes, have short horizontal internodes, whereas the horizontal internodes of small species are thin and long. In contrast, differences between species in the length of vertical internodes are size-independent. Intraspecific variability is, in general, greater for the length of vertical internodes than that for horizontal internodes (Wilcoxon paired ranked sign test, $\mathrm{p}<0.0005$. Fig. 1). The extent of intraspecific variability in horizontal and vertical internodal length was independent of plant size (Fig. 1).

Seagrass horizontal rhizomes extend at rates ranging between 1.2 and $574 \mathrm{~cm} \mathrm{yr}^{-1}$ (Table 2), part (34\%) of this variability being attributable to differences in the length of the internodes of the plants (Table 3), in

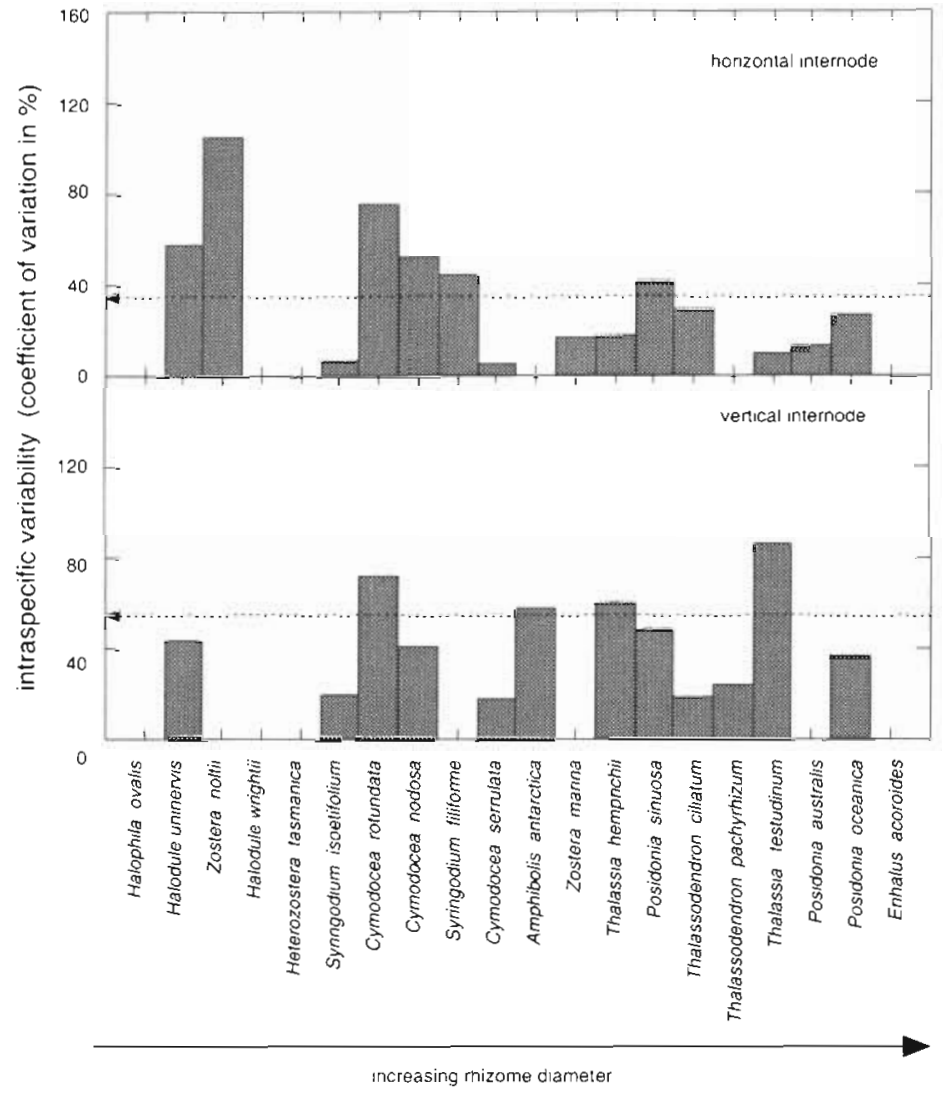

Fig. 1. Intraspecific variability in horizontal (upper panel) and vertical (lower panel) internodal length in the seagrass species examined. Seagrass species are ordered according to their rhizome diameter. Horizontal dotted arrows indicate the average intraspecific variability of seagrass species

agreement with previous findings (Duarte 1991). Most of the variability observed in seagrass horizontal elongation rates was accounted for by differences among species (Table 2), demonstrating that horizontal rhi-

Table 3. Coefficients and standard errors (in parentheses), number of observations ( $n$ ), coefficient of determination ( $\mathrm{R}^{2}$ ), and significance level (F-test, $\mathrm{p}$ ) of the allometric relationships between seagrass rhizome elongation (in $\mathrm{cm} \mathrm{yr}^{-1}$ ), branching patterns, spacer length (in $\mathrm{cm}$ ), and vegetative shoot recruitment and rhizome diameter (in $\mathrm{mm}$ ) or internodal length (in mm). Relationships are of the form $Y=a X^{b}$. ns: no significant relationship

\begin{tabular}{|c|c|c|c|c|c|c|}
\hline Y & $x$ & $a$ & $b$ & $\mathrm{n}$ & $R^{2}$ & $\mathrm{p}$ \\
\hline Horizontal internodal length & Rhizome diameter & $22.4( \pm 1.2)$ & $-0.52( \pm 0.17)$ & 24 & 0.26 & $<0.01$ \\
\hline Horizontal elongation rate & Rhizome diameter & $229( \pm 1.4)$ & $-1.66( \pm 0.29)$ & 25 & 0.58 & $<0.00001$ \\
\hline Vertical elongation rate & Rhizome diameter & & & & & ns \\
\hline Horizontal elongation rate & Horizontal internodal length & $0.56( \pm 2.5)$ & $1.61( \pm 0.35)$ & 23 & 0.47 & $<0.0005$ \\
\hline Vertical elongation rate & Vertical internodal length & $1.7( \pm 1.3)$ & $0.81( \pm 0.19)$ & 18 & 0.49 & $<0.001$ \\
\hline Horizontal branches $\mathrm{yr}^{-1}$ & Rhizome diameter & $3.8( \pm 1.8)$ & $-1.62( \pm 0.43)$ & 21 & 0.39 & $<0.005$ \\
\hline Vertical branches $y^{-1}$ & Rhizome diameter & $2.5( \pm 2.8)$ & $-1.67( \pm 0.65)$ & 10 & 0.39 & $<0.05$ \\
\hline Branching angle $\left({ }^{\circ}\right)$ & Rhizome diameter & $63.1( \pm 1.2)$ & $-0.31( \pm 0.13)$ & 17 & 0.21 & $<0.05$ \\
\hline Spacer length & Rhizome diameter & $2.4( \pm 1.2)$ & $0.37( \pm 0.14)$ & 22 & 0.22 & $<0.05$ \\
\hline Shoots $\mathrm{yr}^{-1}$ horizontal thizome $\mathrm{e}^{-1}$ & Rhizome diameter & $117( \pm 1.6)$ & $-2.19( \pm 0.35)$ & 22 & 0.63 & $<0.00001$ \\
\hline
\end{tabular}




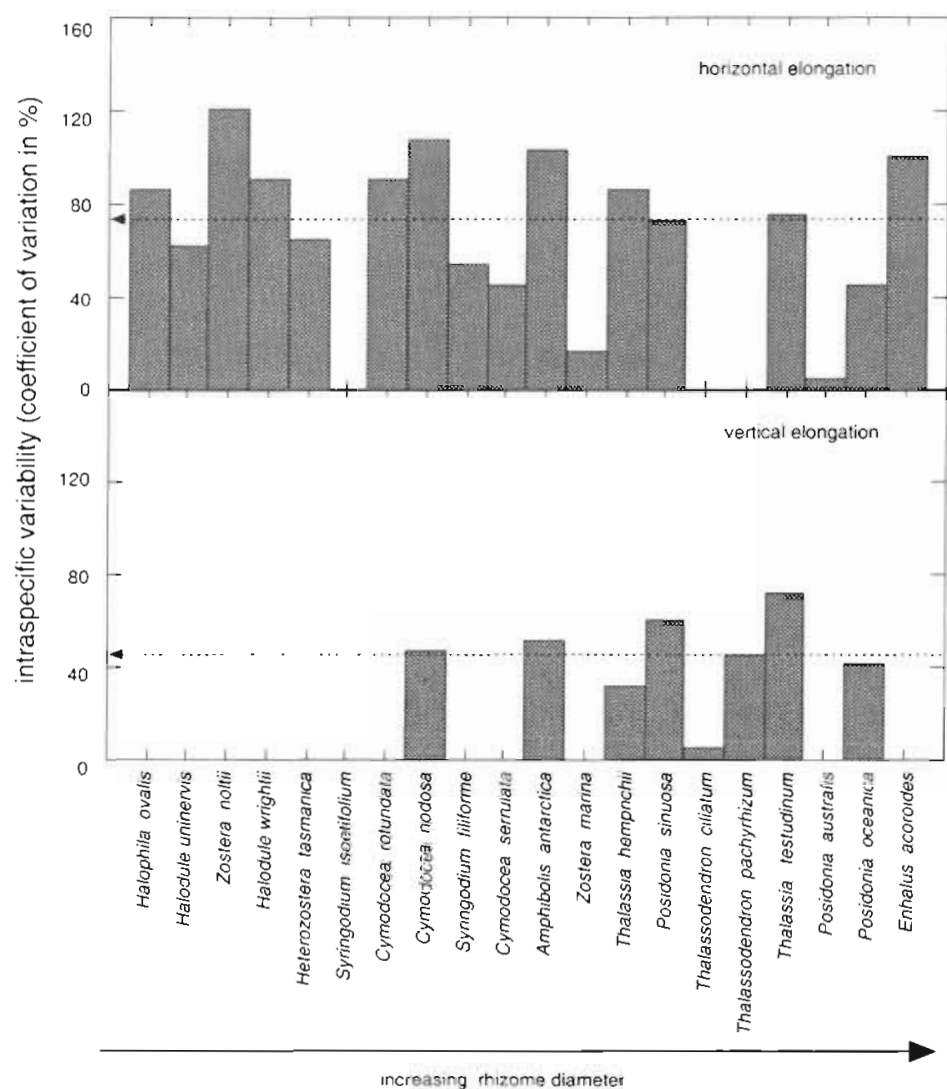

Fig. 2. Intraspecific variability in horizontal (upper panel) and vertical (lower panel) rhizome elongation in the seagrass species examined. Seagrass species are ordered according to their rhizome diameter. Horizontal dotted arrows indicate the average intraspecific variability of seagrass species

zome elongation is largely a species characteristic. The rate of horizontal rhizome elongation of different species was strongly (56\% of the variance) size-dependent, with the horizontal rhizome elongation declining as the $-3 / 2$ power of rhizome diameter (Table 3 ). Species with thin rhizomes (and long internodes) have, therefore, much faster horizontal rates of spread than large species with their thick and short internodes. In addition, the intraspecific variation in horizontal elongation rate is substantial (Table 2, Fig. 2), although independent of seagrass size.

The vertical rhizomes of most seagrasses grow within the sediments, although those of some species (Thalassodendron sp., Amphibolis sp., Heterozostera tasmanica, den Hartog 1970; and sometimes Cymodocea serrulata, Halodule uninervis, and Syringodium filiforme, Duarte et al. 1997, Kenworthy pers. obs.) extend into the water column. Most seagrasses elongate vertically 3 to 100 times slower than they spread horizontally (Table 2). Only the rhizomes of Amphibolis sp. and Thalassodendron pachyrhizum elongate at faster rates vertically than they do horizontally (Table 2). The

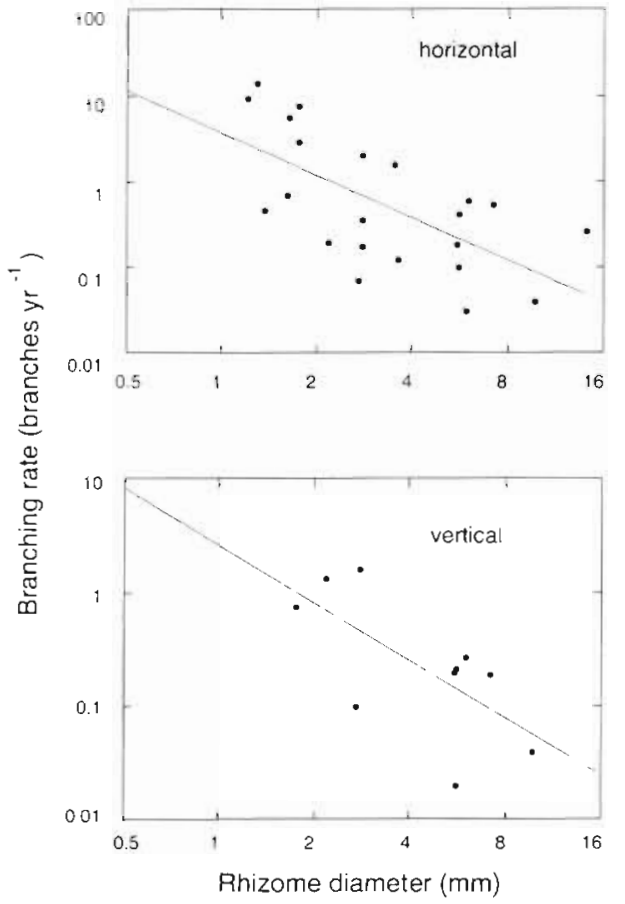

Fig. 3. Relationships between seagrass horizontal branching rate (upper plot), and vertical branching rate (lower plot), and rhizome diameter. Lines represent the fitted regression equations summarised in Table 3

allocation of resources to vertical rhizome growth, however, does not appear to constrain the elongation rate of horizontal rhizomes, for no negative correlation between these rates is apparent $(p>0.5)$. Vertical rhizomes of seagrasses elongage at rates between 0.1 and $34 \mathrm{~cm} \mathrm{yr}^{-1}$ (Table 2), partially reflecting differences in the length of their vertical internodes (Table 3). Seagrass vertical elongation rate is species-specific, but independent of size (Table 3), and the intraspecific variability of vertical growth rates is roughly similar across species (Fig. 2).

The rate at which seagrass clones spread largely depends on their capacity to branch. Seagrass horizontal rhizomes produce a branch for every 6 (Halophila ovalis) to 1800 (Thalassia testudinum) horizontal internodes, this rate tending to decrease as seagrass size, as represented by rhizome thickness, increases (Table 3, Fig. 3). Because both horizontal growth and branching rates increase with decreasing seagrass rhizome diameter, there is a linear increase in horizontal branching rate as horizontal rhizomes elongate faster (regression analysis, slope $=0.034, \mathrm{SE}_{\text {siope }}=0.006, \mathrm{n}=22, \mathrm{R}^{2}=0.61$, $p<0.00001$ ). Variability in horizontal branching rates within species could only be examined, because of the paucity of data, for the Mediterranean species (Cymodocea nodosa, Posidonia oceanica), but our results suggest substantial intraspecific variability in seagrass 
branching rates (coefficient of variation, $\mathrm{CV}=81$ and $99 \%$, respectively). Seagrass horizontal rhizomes usually branch at angles lower than $90^{\circ}$, on average close to $60^{\circ}$ (Table 4, Fig. 4), although branching angles are broader for the smallest species measured (i.e. Halophila ovalis and Zostera noltii, Table 4). The mean branching angle of seagrass species was scaled as the $-1 / 3$ power of rhizome diameter, indicating that small species with thin rhizomes branch at broader angles than larger species with thicker ones (Table 3, Fig. 5). The branching probability of seagrass vertical rhizomes varies greatly, by over 3 orders of magnitude, across seagrass species (Table 4). The annual rate of vertical branch production of seagrass species is also size-dependent, vertical branching rates decreasing as rhizome thickness increases (Table 3, Fig. 3). Moreover, the average vertical branching rate of seagrass species also linearly increases as vertical rhizomes elongate faster (regression analysis, slope $=0.07$, $\mathrm{SE}_{\text {slope }}=0.01, \mathrm{n}=10, \mathrm{R}^{2}=0.72, \mathrm{p}<0.005$ ).

Seagrass horizontal rhizomes add a new shoot for every 1.1 to $7.5 \mathrm{~cm}$ of rhizome produced (Table 2), with about $20 \%$ of the differences in shoot spacing along seagrass rhizomes between species being attributable to size-dependent differences (Table 3). The size

Table 4. Mean horizontal rhizome branching rate $(\mathrm{HB}$, in percent of internodes developing branches), vertical rhizome branching rate (VB, in percent of internodes developing branches), and horizontal branching angle (in degrees) of seagrass species

\begin{tabular}{|c|c|c|c|}
\hline Species & $\mathrm{HB}$ & VB & Angle \\
\hline Amphibolis antarctica & 2.22 & 5.20 & 48 \\
\hline Amphibolis gniffithii & 4.49 & 11.38 & 33 \\
\hline Cymodocea nodosa & 0.59 & 0.89 & 46 \\
\hline Cymodocea serrulata & 8.65 & & 42 \\
\hline Enhalus acoroides ${ }^{\mathrm{d}}$ & 2.54 & & 57 \\
\hline Halophila hawailana ${ }^{\mathrm{a}}$ & 10.30 & & \\
\hline Halophila ovalis & 16.13 & & 72 \\
\hline Heterozostera tasmanica & 25.97 & 4.64 & 56 \\
\hline Halodule uninervis & 1.37 & & 55 \\
\hline Halodule wrightii & 9.20 & & \\
\hline Posidonia angustifolia & 8.52 & 5.50 & 21 \\
\hline Posidonia australis & 7.56 & 2.89 & 21 \\
\hline Posidonia oceanica & 0.51 & 0.53 & 41 \\
\hline Posidonia sinuosa & 5.77 & 6.84 & 19 \\
\hline Syringodium filiforme & 1.64 & & \\
\hline Syringodium isoetifolium & 5.52 & & 58 \\
\hline Thalassia testudinum & 0.06 & & \\
\hline Thalassodendron ciliatum & 1.74 & 0.45 & 31 \\
\hline Thalassodendron pachyrhizum & 1.70 & 0.13 & 51 \\
\hline Zostera marina & 5.22 & & 67 \\
\hline Zostera noltii ${ }^{\mathrm{d}}$ & 2.62 & & 81 \\
\hline Across species CV $(\%)$ & 173 & 120 & 40 \\
\hline
\end{tabular}

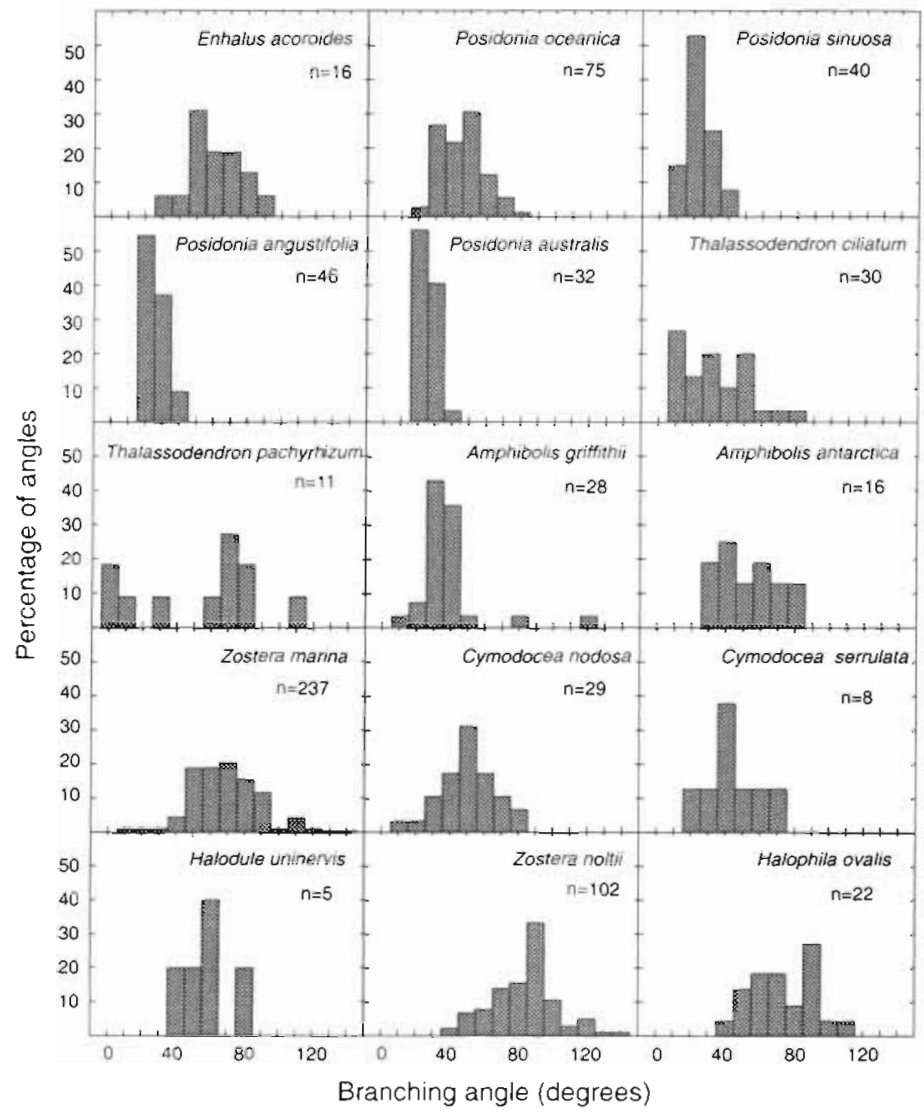

Fig. 4. Frequency distributions of the angles between the horizontal branch and the main horizontal axis of the seagrass species examined. Number of angles measured for each species ( $\mathrm{n}$ j is indicated

dependence of spacer length and elongation rate of horizontal rhizomes leads to annual shoot formation rates (calculated as elongation rate divided by spacer length) ranging from 0.5 (Enhalus acoroides) to 210 (Halophila ovalis) new shoots $\mathrm{yr}^{-1}$ for individual rhizome axes. Shoot formation rate scales as the -2 power

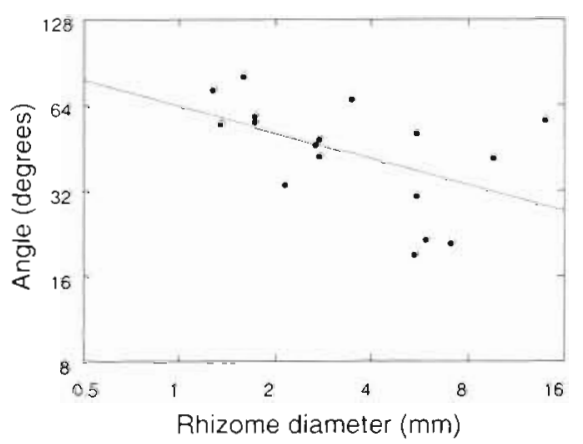

Fig. 5. Allometric scaling of seagrass branching angles to rhizome diameter across seagrass species. Line represents the fitted regression equation summarised in Table 3 


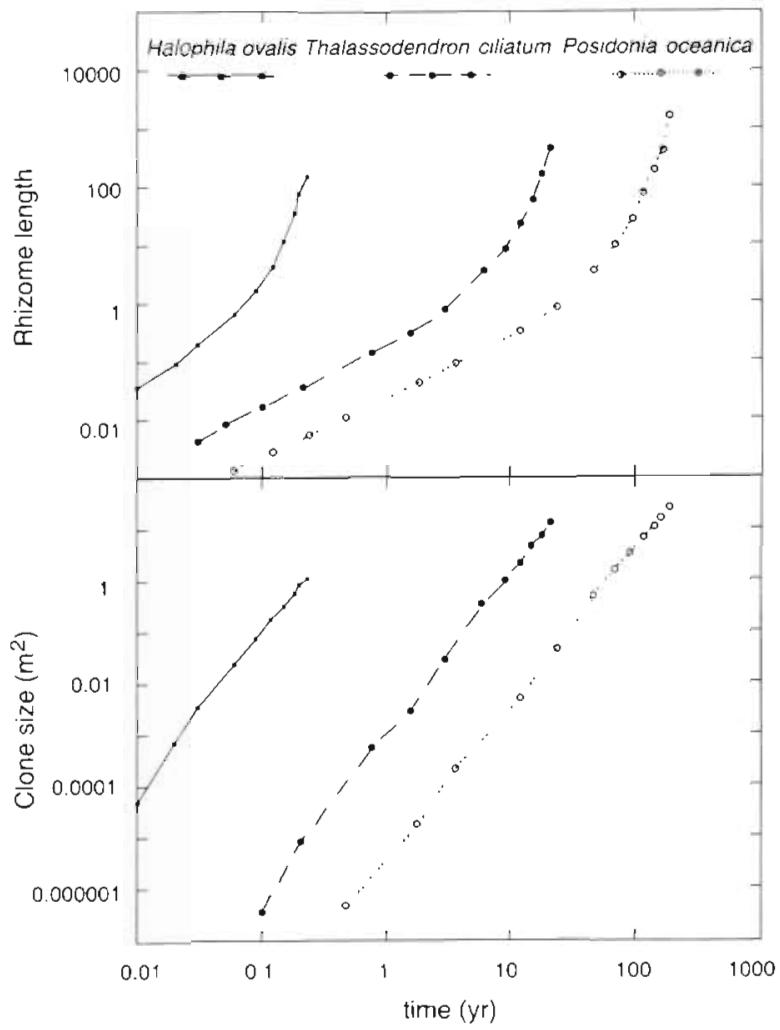

Fig. 6. Temporal change in cumulative rhizome length (upper panel), and the surface occupied (lower panel) by simulated networks of 3 contrasting seagrass species (Halophila ovalis, Thalassodendron ciliatum, Posidonia oceanica), using their horizontal internodal length (Table 2), rhizome elongation rate (Table 2), and horizontal branching rates (Table 4)

of rhizome diameter (Table 3), demonstrating a much slower clonal growth of large compared to small seagrass species. Because vertical rhizomes add a new shoot for each branch produced, vertical branching yields between 0.04 (i.e. Posidonia oceanica) and 1.6 (Amphibolis antarctica) new shoots per vertical rhizome per year; this rate also decreases as rhizome thickness increases (Table 3).

The broad repertoire of seagrass rhizome and clonal growth programmes is conducive to widely different rates of space occupation and capacities to maintain seagrass meadows. The results derived from the simulation of the development of seagrass rhizome networks indicate that the cumulative rhizome length increases linearly during the initial stages, and later according to a double exponential function for the three 3 species simulated (i.e. Halophila ovalis, Thalassodendron ciliatum, Posidonia oceanica, Fig. 6). The transition from the lineal to the double exponential rhizome spread is set by the time required by a rhizome to produce the first branch (i.e. $11 \mathrm{~d}, 3 \mathrm{yr}$, and $22.6 \mathrm{yr}$ for $H$. ovalis, $T$. ciliatum, and $P$ oceanica, respectively;

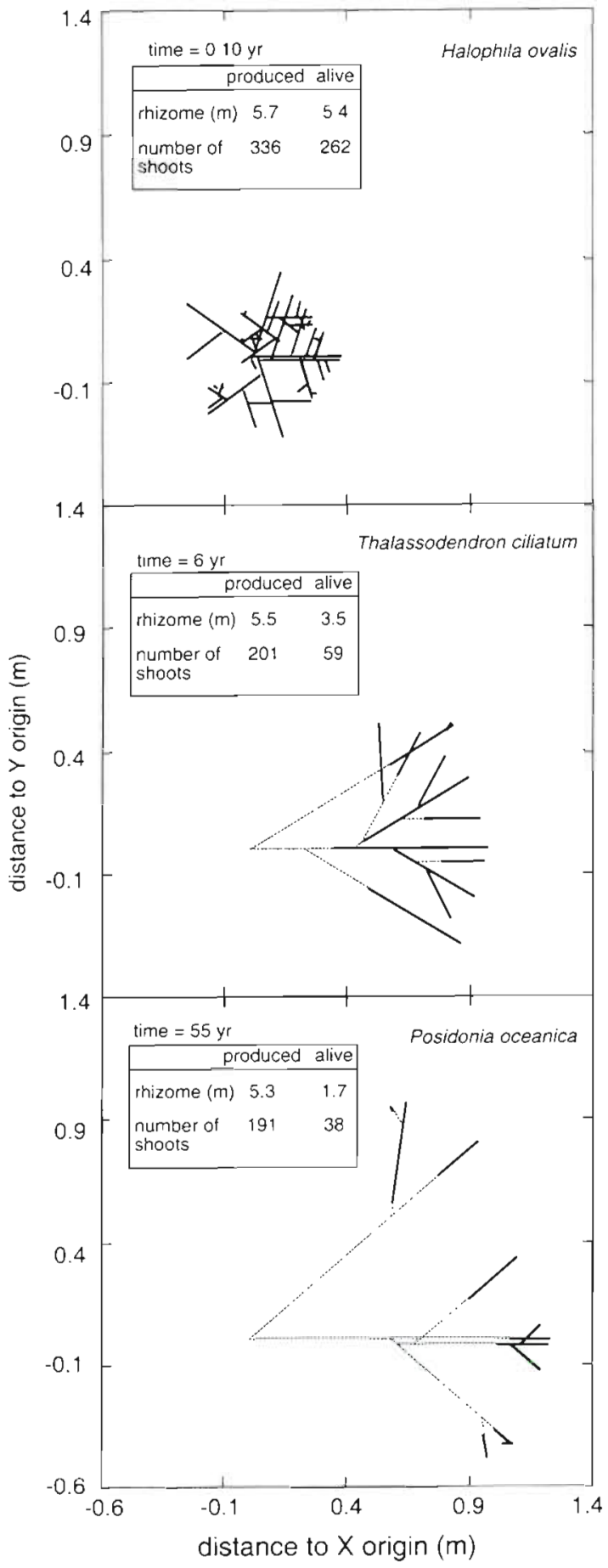

Fig. 7 Simulated rhizome networks after having produced ca $5 \mathrm{~m}$ of rhizome for 3 contrasting seagrass species (Halophila ovalis, Thalassodendron clliatum, Posidonia oceanica), using their horizontal internodal length (Table 2), rhizome elongation rate (Table 2), and horizontal branching rates (Table 4). Time required to develop the networks and rhizome length and number of shoots produced and surviving since initiation of clonal spread are indicated. Dashed lines show the spatial distribution of the rhizomes and shoots produced, and solid lines the distribution of surviving rhizomes and shoots 
Tables 2 \& 4). Variability in branching rate and rhizome elongation constrains the time scales of rhizome network development. The production of a seagrass network with $5 \mathrm{~m}$ of horizontal rhizome requires 0.10 yr for the small seagrass $H$. ovalis, 6 yr for the midsized species $T$. ciliatum, and $55 \mathrm{yr}$ for the large species $P$. oceanica (Fig. 7). The production of $5 \mathrm{~m}$ rhizome network would involve the recruitment of 336, 201, and 191 shoots for $H$. ovalis, T. ciliatum, P. oceanica, respectively (Fig. 7). Moreover, the spread and spacefilling efficiencies of seagrasses vary substantially across these species. A clone of the small species $H$. ovalis with a $5 \mathrm{~m}$ rhizome network occupies an area $1 / 4$ of the area colonised by a clone of the large $P$. oceanica with $5 \mathrm{~m}$ rhizome network (Fig. 7).

\section{DISCUSSION}

The results presented demonstrate that seagrass species display a wide repertoire of growth programmes, as reflected in broad differences in rhizome elongation, shoot proliferation, and branching rates. Much (between 40 and $173 \%$ ) of the variability of seagrass horizontal rhizome and clonal growth programmes is species-specific, largely $(21$ to $63 \%$ of the variance) associated with differences in size among species, although individual species also show important variability. The strong species-specific nature of seagrass rhizome and clonal growth programmes exceeds that of other components of seagrass productivity, such as leaf growth (Duarte 1991). The strong species dependence of seagrass clonal growth demonstrated here had been postulated by Tomlinson (1974), based on the observation of their organised vegetative morphology of seagrasses, and supports previous analyses of horizontal rhizome elongation (Duarte 1991).

The close scaling of horizontal rhizome elongation programmes to rhizome diameter (Table 3) may reflect differences in the construction costs of horizontal rhizomes, which increased as the 3 rd power of rhizome diameter. Hence, small species, with thin rhizomes, should be able to produce much longer rhizomes than seagrasses with thick ones given a similar allocation of resources. Indeed, the volume of rhizome material produced annually by seagrasses (horizontal rhizome volume $=$ horizontal rhizome elongation $\times$ surface area $=$ diameter ${ }^{-1.66} \times$ diameter $^{2}=$ diameter $^{034}$ ) increases with increasing seagrass diameter, consistent with the observation that the relative allocation of resources to belowground production increases as seagrass size increases (Duarte \& Chiscano 1998). Size-dependent constraints, however, do not help to account for differences in vertical rhizome elongation rate.
Seagrass species with thick rhizomes branch more sparsely than species with thinner ones (Table 3, Fig, 3), as observed for clonal plants on land, such as forest herbs and dwarf shrubs (cf. Sobey \& Barkhouse 1977). Despite the fact that the rate of annual seagrass branching decreases with increasing seagrass size, the longer life-span of large species (Duarte 1991) suggests that large seagrasses may maintain more complex rhizome networks than smaller ones. An increase in the number of branches with size has been demonstrated to be a common characteristic of branched networks, such as trees or rivers (Leopold 1971, Stevens 1974). However, our data, combined with estimates of seagrass shoot life-span, do not show any clear trend between seagrass size and the number of horizontal or vertical branches developed during the life of shoots. Moreover, the amount of extant branches on a network depends on the rate of branch decay, for which no estimates are available.

The extent of intraspecific variability of seagrass rhizome and clonal growth (Figs. 1 \& 2) reflects intrinsic differences among the plants, their ability to colonise contrasting environments, and their ability to survive environmental changes of different magnitude. Intraspecific variability in horizontal rhizome elongation should be largely derived from morphological responses to local variability in resource availability (nutrients, light) and plant density. The intraspecific variability quantified suggests that seagrasses may have the potential to exhibit foraging behaviour when growing in less favourable sites, similar to that demonstrated in some clonal herbs (e.g. Glecoma hederacea, Slade \& Hutchings $1987 \mathrm{a}, \mathrm{b})$. In addition, changes in horizontal rhizome elongation rate may reflect densitydependent constraints. Seagrass horizontal rhizomes growing at the edge of seagrass meadows (e.g. Thalassia testudinum, Patriquin 1973), or extending over bare sediments (e.g. Cymodocea nodosa, Duarte \& SandJensen 1990), elongate at faster rates than those growing within the interior of well-developed meadows (e.g. Thalassia testudinum, Gallegos et al. 1993; Cymodocea nodosa, Marbà et al. 1996a).

The intraspecific variability in vertical rhizome growth probably reflects, in species in which vertical rhizomes grow underground, fluctuations in sediment accretion. The stimulation of vertical seagrass growth of surviving shoots by sand accretion has been experimentally demonstrated for 6 seagrass species (Marbà \& Duarte 1994, Duarte et al. 1997). Conversely, intraspecific variability in vertical rhizome growth programmes in seagrasses in which vertical rhizomes elongate within the water column (e.g. Thalassodendron sp.) may partly reflect changes in light intensity. For instance, vertical growth in $T$. ciliatum depends on shoot age, elongating at the fastest rates during the 
first year, when the shoot is highly shaded, and then decreasing as the leaves reach the canopy and, thus, light availability improves (Duarte et al. 1996).

The broad repertoire of seagrass rhizome growth programmes enables Halophila ovalis to extend its rhizomes over surfaces at time scales of months, whereas the development of comparable rhizome networks of Thalassodendron ciliatum and Posidonia oceanica require time scales of decades and centuries, respectively (Fig. 6). Despite the different time scales of clone development among species, the area occupied by the clone increases as time ${ }^{3}$ for all 3 species (Fig. 6). The length of seagrass rhizome produced during the development of the clone, therefore, is scaled as the 1.5 power of time (i.e. $L-T^{3 / 2}$ ). The fact that the lineal dimension of seagrass rhizome networks is scaled as the 1.5 power of time, and not linearly as otherwise expected, implies that branching patterns are a key factor for the occupation of space by seagrasses.

Differences in rhizome and clonal growth programmes also result in different strategies to develop and maintain the networks. Rhizome growth programmes lead small species (Halophila ovalis) to have the lowest spread efficiency (in $\mathrm{m}^{2}$ of area covered $\mathrm{m}^{-1}$ of rhizome), whereas it is greatest for the largest species (Posidonia oceanica). The different colonisation efficiency predicted across seagrass species derives from the fact that $P$. oceanica networks grow along a dominant direction, whereas $H$. ovalis ones develop in a spiral pattern (Fig. 7). Differences in the growth pattern of rhizome networks exclusively results from differences in branching angles between species. A small branching angle is conducive to centrifugal growth, whereas a broad one leads to a spiral growth pattern (Stevens 1974). These differences in clonal growth form are clearer when looking at the surviving portions of the clones. We used published shoot mortality rates for these species (Vermaat et al. 1995, Marbà et al. 1996b, Duarte et al. 1997) to estimate the length and spatial distribution of surviving rhizome and shoots in the simulated $5 \mathrm{~m}$ rhizome networks. The surviving rhizomes and shoots in a $P$. oceanica network are distributed along the periphery of the network, showing that a clone of this species propagates centrifugally (Fig. 7). In contrast, the surviving rhizome and shoots in the $H$. ovalis network are distributed across the whole network, reflecting the spiral growth form of the clones of this species (Fig. 7). These different strategies of clonal growth lead $P$. oceanica, the climax species in the Mediterranean, to display a guerrilla growth type (cf. Lovett-Doust 1981), with high spreading efficiency and low space-filling capacity, whereas $H$. ovalis, a pioneer species, develops its clones according to a phalanx growth type (cf. Lovett-Doust 1981), with low spreading and high-space filling efficiency.
The coupling between rhizome growth and shoot recruitment implies that small seagrass species (Halophile ovalis) maintain shoot fluxes $>900$-fold greater than large ones (Posidonia oceanica, Fig. 7). The meadows of small seagrass species, therefore, can only be sustainable (i.e. reach a steady state in shoot density) if shoot mortality is high. Conversely, the slow clonal growth of large seagrasses can only yield a stable meadow if the shoots are long-lived. The size dependence of shoot longevity required in order to maintain stable meadows has indeed been confirmed through comparative analyses (Duarte 1991). Moreover, the sparse, clumped distribution of populations of Enhalus acoroides, the largest seagrass species, arise because of the relatively short life-span of their shoots $(<12 \mathrm{yr}$, Vermaat et al. 1995) compared to their slow rhizome growth (5.3 $\mathrm{cm} \mathrm{yr}^{-1}$, Vermaat et al. 1995), which prevents the development of crowded stands (i.e. meadows).

In summary, our results show that seagrasses display a large, order-of-magnitude, variability in rhizome elongation, branching patterns and clonal growth. These differences are, to a large extent, size-dependent, involving lower horizontal elongation rates, shoot production rates, and branching rates and angles as plant size increases. Seagrass species retain, however, a sizeable intraspecific variability in their clonal growth programme which should allow adaptive responses of clonal growth. Space occupation by seagrasses is closely controlled by their rhizome growth programme, programmes in which, in addition to the differences in time scales derived from differences in elongation rate, the angle and rate of branching forces major differences in the pattern and efficiency of space occupation. Shallow angles and sparse branching, characteristic of large species, results in a centrifugal, guerrilla growth pattern, whereas the profuse branching and broad angles characteristic of small species results in a spiral, phalanx growth pattern leading to an inefficient spread of the clone. The importance of clonal growth patterns render these properties primary components of the development and maintenance of seagrass meadows.

Acknowledgements. This work was produced from a decade of field work under projects funded by Integrated Actions between Spain and Portugal and Mexico of the Spanish Ministry of Education and Culture and the Spanish Research Council (CSIC), a grant from the 'Fundación Ramón Areces', 2 projects funded by the European Commission (CI1 ${ }^{\circ}$-CT910952; TS $3^{\circ}$-CT94-0301; STD II and STD III programmes), and a travel grant from the Catalan Research Commission (CIRIT). The Spanish Ministry of Education and Culture supported N.M. We are grateful to M. F. Pedersen for providing unpublished data. We are indebted to F. J. R. Meysman for designing the model to simulate seagrass clonal growth and for stimulating discussions during the course of this work. 


\section{LITERATURE CITED}

Angevine MW, Handel SN (1986) Invasion of forest floor space, clonal architecture, and population growth in the perennial herb Clitonia borealis. J Ecol 74:547-560

Batschelet E (1981) Circular statistics in biology. Academic Press, London

Bell AD, Roberts D, Smith A (1979) Branching patterns: the simulation of plant architecture. J Theor Biol 81:351-375

Bell AD, Tomlinson PB (1980) Adaptive architecture in rhizomatous plants. Bot J Linn Soc 80:125-160

Brouns JWM (1987) Growth patterns in some Indo-WestPacific seagrasses. Aquat Bot 28:39-61

Cain ML (1990) Models of clona] growth in Solidago altissima. $\mathrm{J} E \operatorname{col} 78: 27-46$

Cain ML, Dudle KA, Evans JP (1996) Spatial models of foraging in clonal plant species. Am J Bot 83:76-85

Calmet D, Boudouresque CP, Meinesz A (1988) Memorization of nuclear atmospheric tests by rhizomes and scales of the mediterranean seagrass Posidonia oceanica (Linnaeus) Delile. Aquat Bot 30:279-294

Cayé G. Meinesz A. (1985) Observations on the vegetative development, flowering and seedling of Cymodocea nodosa (Ucria) Ascherson on the Mediterranean coasts of France. Aquat Bot 22:277-289

Cunha APM (1994) Aplicaçao das técnicas de reconstruçao ao estudo da dinamica populacional de Cymododea nodosa (Ucria) Ascherson. MS thesis, Universidade do Algarve, Faro

den Hartog C (1970) The seagrasses of the world. North Holland Publ, Amsterdam

Duarte CM (1991) Allometric scaling of seagrass form and productivity. Mar Ecol Prog Ser 77:289-300

Duarte CM (1995) Submerged aquatic vegetation in relation to different nutrient regimes. Ophelia 41:87-112

Duarte CM, Chiscano CL (1998) Sagrass biomass and production: a reassment. Aquat Bot (in press)

Duarte CM, Sand-Jensen K (1990) Seagrass colonisation: patch formation and patch growth in Cymodocea nodosa. Mar Ecol Prog Ser 65:193-200

Duarte CM, Marbà N, Agawin N, Cebrián J, Enríquez S, Fortes MD, Gallegos ME, Merino M. Olesen B, SandJensen K, Uri J, Vermaat J (1994) Reconstruction of seagrass dynamics: age determinations and associated tools for the seagras ecologist. Mar Ecol Prog Ser 107:195-209

Duarte CM, Hemminga MA, Marbà N (1996) Growth and population dynamics of Thalassodendron ciliatum. Aquat Bot 55:1-11

Duarte CM, Terrados J, Agawin NSR, Fortes MD, Bach $S$, Kenworthy WJ (1997) Response to a mixed Philippine seagrass meadow to experimental burial. Mar Ecol Prog Ser 147:285-294

Gallegos M, Merino M, Marbà N, Duarte CM (1993) Biomass and dynamics of Thalassia testudinum in the Mexican Caribbean: elucidating rhizome growth. Mar Ecol Prog Ser 95:185-192

Gallegos M, Merino M, Rodríguez A, Marbà N, Duarte CM (1994) Growth patterns and demography of pioneer Caribbean seagrasses (Halodule wrightii and Syringodium filiforme). Mar Ecol Prog Ser 109:99-104

Herbert DA (1986) The growth dynamics of Halophila hawaiiana. Aquat Bot 23:351-360

Jacobs RPWM (1979) Distribution and aspects of the production and biomass of eelgrass, Zostera marina L., at Roscoff, France. Aquat Bot 7:151-172

Kenkel NC (1993) Modeling Markovian dependence in populations of Aralia nudicaulis. Ecology 74:1700-1706
Leopold LB (1971) Trees and streams: the efficiency of branching patterns. J Theor Biol 31:339-354

Lovett-Doust L (1981) Population dynamics and local specialization in a clonal perennial (Rannunculus repens). 1. The dynamics of ramets in contrasting habitats. J Ecol 69 : $743-755$

Marbà N, Duarte CM (1994) Growth response of the seagrass Cymodoced nodosa to experimental burial and erosion. Mar Ecol Prog Ser 107:307-311

Marbà N, Duarte CM (1995) Coupling of seagrass (Cymodocea nodosa) patch dynamics to subaqueous dune migration. J Ecol 83:381-389

Marbà N. Duarte CM (1997) Interannual changes in seagrass (Posidonia oceanica) growth and environmental change in the Spanish Mediterranean littoral zone. Limnol Oceanogr 4.2:800-810

Marbà N, Gallegos M, Merino M, Duarte CM (1994) Vertical growth of Thalassia testudinum: seasonal and interannual variability. Aquat Bot 47:1-11

Marbà N, Cebrián J, Enríquez S, Duarte CM (1996a) Growth patterns of Western Mediterranean seagrasses: speciesspecific responses to seasonal forcing. Mar Ecol Prog Ser 133:203-215

Marbà N, Duarte CM, Cebrián J, Enriquez S, Gallegos ME, Olesen B, Sand-Jensen K (1996b) Growth and population dynamics of Posidonia oceanica in the Spanish Mediterranean coast: elucidating seagrass decline. Mar Ecol Prog Ser 137:203-213

Meinesz A, Cayé G, Loquès F, Molenaar H (1991) Growth and development in culture of orthotropic rhizomes of Posidonia oceanica. Aquat Bot 39:3657-377

Niklas KJ (1994) Plant allometry: the scaling of form and process. University of Chicago Press, Chicago

Patriquin DG (1973) Estimation of growth rate, production and age of the marine angiosperm Thalassia testudinum König. Carib J Sci 13:111-123

Patriquin DG (1975) 'Migration' of blowouts in seagrass beds at Barbados and Carriacou, West Indies, and its ecological and geological implications. Aquat Bot 1:163-189

Pérez M, Duarte CM, Romero J, Sand-Jensen K, A.Jcoverro T (1994) Growth plasticity in Cymodocea nodosa stands: the importance of nutrient supply. Aquat Bot 47:249-264

Ramírez-García P, Lot A, Duarte CM, Terrados J, Agawin NSR (1998) Bathymetric distribution, biomass and growth dynamics of intertidal Phyllospadix scouleri and Phyllospadix torreyi in Baja California (México). Mar Ecol Prog Ser 173:13-23

Sand-Jensen K (1975) Biomass, net production and growth dynamics in an eelgrass (Zostera marina L.) population in Vellerup Vig, Denmark. Ophelia 14:185-201

Slade AJ, Hutchings M.J (1987a) The effects of nutrient availability on foraging in the clonal herb Glecoma hederacea. $J$ Ecol 75:95-112

Slade AJ, Hutchings MJ (1987b) The effects of light intensity on foraging in the clonal herb Glecoma hederacea. J Ecol $75: 639-650$

Sobey DG, Barkhouse P (1977) The structure and rate of growth of the rhizomes of some forest herbs and dwarf shrubs of the New Bruswick-Nova Scotia Border Region. Can Field vat 91:377-383

Stevens PS (1974) Patterns in nature. Atlantic Monthly Press, Boston

Terrados J (1997) Is light involved in the vertical growth response of seagrasses when buried by sand? Mar Ecol Prog Ser 152:295-299

Terrados J, Duarte CM, Kenworthy WJ (1997) Experimental evidence for apical dominance in the seagrass Cymodocea 
nodosa. Mar Ecol Prog Ser 148:263-268

Terrados J, Ros JD (1992) Growth and primary production of Cymodocea nodosa (Ucria) Ascherson in a Mediterranean coastal lagoon: the Mar Menor (SE Spain). Aquat Bot 43: $63-74$

Tomlinson PB (1974) Vegetative morphology and meristem dependence. The foundation of productivity in seagrasses. Aquaculture 4:107-130

Vermaat J, Agawin N, Duarte CM, Fortes MD, Marbà N, Uri J (1995) Meadow maintenance, growth and produc-

Editorial responsibility: Otto Kinne (Editor),

Oldendorf/Luhe, Germany tivity of a mixed Philippine bed. Mar Ecol Prog Ser 124: $215-225$

Vogel S (1981) Life in moving fluids. Princeton University Press, Princeton

Williams SL (1987) Competition between the seagrasses Thalassia testudinum and Syringodium filiforme in a Caribbean lagoon. Mar Ecol Prog Ser 35:91-98

Zieman JC (1974) Methods for the study of the growth and production of the turtle grass, Thalassia testudinum König. Aquaculture 4:139-143

Submitted: March 6, 1998; Accepted: August 12, 1998

Proofs received from author(s): November 13,1998 